\title{
Image assets: the care and feeding of a different breed of digital assets
}

\section{David Norris}

is the CEO of OnRequest Images, the world's leading provider of custom imagery. A seasoned executive with more than 20 years of broad business experience, OnRequest Images unites David's lifelong passion for photography with a deep understanding of technology to help corporations build brand equity through custom imagery.

Keywords: stock photography, image management, cataloging, keywording, JPG, TIF, file size, licensing rights, image use

Abstract Over the last decade, as the use of digital images and the potential for liability associated with their use increased, companies of all sizes have begun to investigate solutions to better manage their image assets. These solutions must address the unique challenges of managing images, which are distinctly different from other types of digital assets. Using images in a corporate environment has the potential to create liability that must be mitigated with controlled access and a defined process for image management. Traditional enterprise asset management systems are not ideally suited for the complex issues that arise when considering how images are searched, retrieved, used and tracked in a corporate environment. This article will outline six key differentiating factors that must be considered as an image management system is planned and will offer insight into the approach corporations should take with regard to their image assets.

Journal of Digital Asset Management (2006) 2, 223-230. doi:10.1057/palgrave.dam.3650036
David Norris

CEO, OnRequest Images,

Tel: + 2063820192

Fax: +2067746075

Email: david.norris@

onrequestimages.com

\section{BACKGROUND}

Corporate use of photography in advertising, marketing and other materials has increased dramatically in the last 15 years. Growth in the number of corporate image assets accelerated during the 1990s as photography migrated from an almost entirely analog form to almost entirely digital form, making it much easier for companies to find, license and use imagery.

As companies use imagery more frequently, they also need to deploy more robust systems to store, retrieve and track their use.

Companies typically acquire image assets from three primary sources:

- Stock photography providers with existing collections.

- Professional photographers or agencies creating custom photography.

- In-house teams creating graphic content (for example, web content).

In the first two cases, the images are typically licensed by the company for use, rather than purchased outright. In the third case, content created by the company usually becomes a wholly owned company asset. ${ }^{1}$

Licensed images can be "rights managed," meaning the image can only be used in certain defined ways (ie for printed marketing collateral pieces but not for web site use), or they can be "royalty-free," where fewer restrictions are placed on how the image may be used. Because each image may have a unique set of permissions, the task of tracking these restrictions across hundreds or thousands of images can be daunting.

Historically, companies did not store or manage image assets themselves. Prior to the digitization of the stock photography industry, licensed images were often delivered in film transparency form. A company would license an image for a specific one-time use and then return the transparency to the photographer or agency when production was complete. Internal design teams relied on the agency or photographer to supply new images as they were needed. Surprisingly, this labor-intensive 
method was still in use as recently as the early 1990s.

Today, with most licensed images delivered in digital format, many companies find they now have thousands of image assets distributed throughout their corporate file servers, or on discs in office drawers. As most images are licensed assets, the risk of license violations associated with unchecked access to and use of these distributed images can be considerable and speaks to the need for better processes to manage image use.

The sophistication of corporate processes surrounding image management and use varies widely by industry sector and company size. As companies' processes for managing images mature, they become more aware of the benefits of using a formal image management system, including risk mitigation and costs savings.

Large media companies like Discovery Channel, Disney and Time/Warner were early adopters of image management systems while small to mid-size companies are just now realizing how much these types of systems can reduce costs and corporate liability. And yet, while interest in image management systems is growing, industry estimates indicate that fewer than 20 per cent of US companies have a robust image management solution in place today

\section{DISTINCT ATTRIBUTES OF IMAGE ASSETS}

Images are distinctly different from other corporate digital assets. They can have significant impact on a company's brand, and have unique characteristics that must be considered, such as complex metadata and keywording requirements, varied file formats and license restrictions on use, among others. These characteristics have an effect on how a company decides to manage image assets. The following elements should be considered when determining an appropriate image management system.

\section{Brand impact}

Images and how they are used have a direct impact on a corporate brand's strength and sustainability. Inconsistent use of images can lead to confusion about a brand's signature look-andfeel. Having control over which images are available for use in a company's advertising or marketing campaigns is one of the primary reasons image management system are increasingly being implemented. If a company does not know what images are in use, or does not have control over who can access and select them, it may find its brand at risk.

In companies with multiple business divisions, tracking exactly which images have been used, and for which products or campaigns, can be extremely challenging. A robust image management system can provide details on who licensed or commissioned the original image, what campaigns the image has been used in, and in which geographies the image has been displayed. The image management system can put restrictions on who can access these images thereby supporting the marketing teams' efforts to build a visually consistent brand.

Another important element is the "freshness" or timeliness of the images used to support the brand. As brands evolve over time, so does their look-and-feel. With no system in place to manage a company's image assets, it is easy for old, off-brand images to remain in the files and perhaps find their way into use, even if they are no longer appropriate. A properly constructed image management system can ensure that only approved, current images are available.

\section{Licensed asset}

As mentioned earlier, most of the images that companies use are licensed rather than owned. These licenses carry specific permissions that define, along with other restrictions, how the image may be used, and for how long. Violation of the terms of the license can create significant corporate liability and financial risk.

Without an image management system in place, companies cannot be sure how images in their files or on their servers are being used or what license terms they may be in violation of. In fact, liability concerns are often the first catalyst for corporate consideration of image management systems. Liability for violations of image license terms and copyright can run into the hundreds of thousands of dollars, if not millions.

An image management system can reduce corporate liability by providing a central tracking system for license terms and use, making it a key element of many companies' risk mitigation strategy. Features in the system 
such as an automatic notice of pending license term expiration allowing for the timely renewal of permissions to avoid violations can be included.

\section{SIDEBAR: WHY TRACKING IMAGE USE COUNTS}

In 2000, photographer Brian Harness shot several images of the Bradford Lincoln Park Hotel in Dallas for the firm that designed the building, Merriman Architects. Harness registered the images with the copyright office and Merriman purchased prints of the photos for promotional purposes. Later that year, Harness met with John Wilson, an officer and director in Intervest, the company that manages the hotel. Wilson had seen Harness' pictures of the hotel in the architect's office and decided to purchase prints from Harness.

Harness says he did not give Wilson permission to use the photos for publication, and became suspicious in 2003 when he received a call from a new ad agency hired to do work for the hotel partnership. The agency was trying to buy all of Harness' rights to the photos.

A Google search for the name of the hotel confirmed Harness' hunch: One of his pictures was being used in hotel promotions without his permission. Harness also cited several other examples of infringement, including a printed flier that used the photos.

The case was finally settled after mediation. Each side provided expert testimony as to how much the copyright infringement was worth; they negotiated the amount of $\$ 135,000 .^{2}$

This example shows companies that do not have a system that can track where an image came from and what use rights have been secured - risk significant financial penalties.

\section{Access and tracking controls}

Access control is another key aspect of image management. The ability to manage the various levels of access necessary, such as who has permission to upload, download or edit images, helps a company avoid license violations that lead to corporate liability. Additionally, this level of control helps protect the company's brand from damage through inconsistent use of images that do not support or reflect the brand appropriately.

For example, it is permissible for companies to use images for design layout purposes without having the license to use the image in the final product. A central image management system allows for tracking of these "comp" images (images used for composition prior to licensing for the actual use). Without robust tracking it is very easy for "comp" images to accidentally end up in final use without a license being acquired, which can further expose a company to liability.

A robust system also allows for tracking and reporting of image use. The system administrator — and their assigned designates - need to know who is downloading images, for what purpose and when. This granular knowledge of image use helps mitigate the risk of license violations.

Without a centralized image management system in place, companies can struggle with defining who is responsible for managing image assets - tracking license expirations, patrolling appropriate use and keeping the image collection fresh.

The amount of time required to track access and use of collections of images that may number in the thousands suggest that companies may want to consider hosted solutions for image management. Working with a hosted provider who specializes in image management can take significant operational burden off internal resources, allowing more energy to be focused on policies and practices.

\section{Variability in size, format and use}

Managing image and graphic files presents unique challenges, given the range of sizes of these files. Typical file sizes for images designed for use in marketing and advertising range from $20 \mathrm{MB}$ to $100 \mathrm{MB}$ and larger. Corporate image collections can range from a few hundred to tens of thousands of images and as a result, the sheer amount of data being managed can cause service disruption to networks and servers. Reliability, fault tolerance, failure and disaster recovery must all be considered and are all complicated by the large size of image files. The size of digital image files continues to increase, complicating the operational issues at hand. These storage and management 


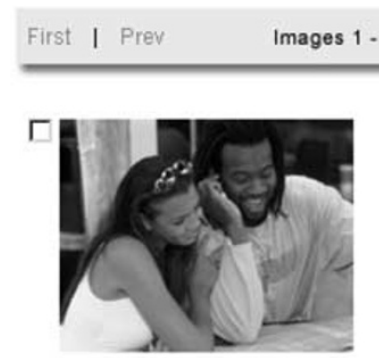

ID: 114473

Collection: People and Product

Provider: OnRequest Images

Format: $4605 \times 3646$ TIF

enlarge download similars

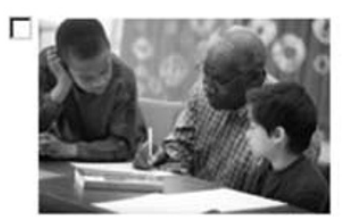

ID: 152955

Collection: 2 collections ...

Provider: OnRequest Images

Format: $5019 \times 3346$ TIF

enlarge download similars

First I Prev

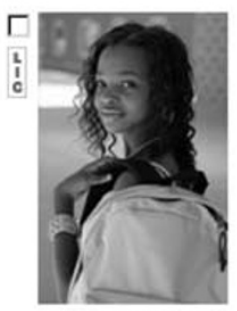

ID: 129670

Collection: 2 collections...

Provider: OnRequest Image

Format: $3305 \times 5080$ TIF

enlarge download similars

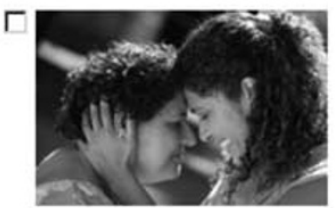

ID: 139279

Collection: 3 collections ...

Provider: OnRequest Images

Format: $4064 \times 2704$ TIF

enlarge download similars

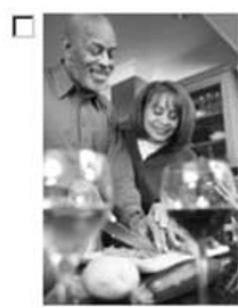

ID: 151643

Collection: Senior Lifestyle

Provider: OnRequest Image

Format: $2704 \times 4064$ TIF

enlarge download similars

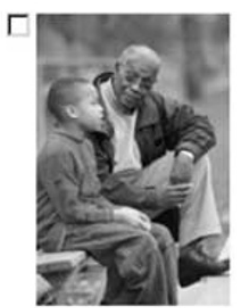

ID: 153355

Collection: 2 collections

Provider: OnRequest Images

Format: $3286 \times 4965$ TIF

enlarge download similars

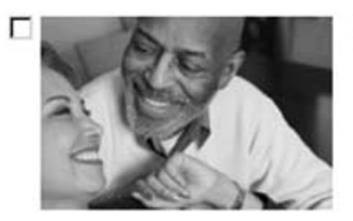

ID: 154494

Collection: Senior Lifestyle

Provider: OnRequest Images

Format: $5024 \times 3342 \mathrm{TIF}$

enlarge download similars

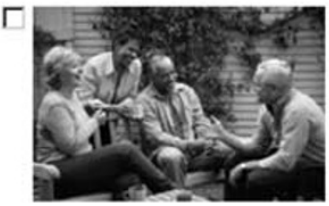

ID: 154832

Collection: Senior Lifestyle Provider: OnRequest Image Format: $4992 \times 3328 \mathrm{TIF}$

enlarge download similars

Figure 1: Thumbnail or filmstrips are necessary viewing elements for an image management system to be an effective tool across an organization. The ability to manage the varied aspects of an image (ie format, license, collections) and organize them on the fly are also critical elements to consider when evaluating a solution

implications have encouraged companies to look at hosted image management solutions to minimize hardware and operational costs.

The ideal image management system offers rapid retrieval of images based on the specifications requested by the user. For example, an image file may be stored in $100 \mathrm{MB}$ size for high-resolution print output, but someone accessing the file may only need a screen resolution version for a presentation. Images should be readily available in multiple formats and sizes.

Any image management system considered must also be able to handle the many different file types common to image and graphic assets, including but not limited to TIF, JPG, GIF and PDF. In many cases, companies are also beginning to look at managing time-based media such as film and video, which have specific file formats distinct from still images.
A particular challenge for companies evaluating their image management processes and needs is determining the standards for image file formats, sizes and the attached data required to effectively manage the asset. This is another area where a hosted solution can save the company significant time and work.

\section{Searching, keywording and metadata needs}

Companies will interact with the image management system frequently — much more often than they might with other classes of digital assets. Image use is part of the workflow of many groups within a company and this makes the user interface, including search, retrieval and display of the image files, critical.

By their nature, images are visual - it is more intuitive to understand an image by viewing it than by listening to someone describe 


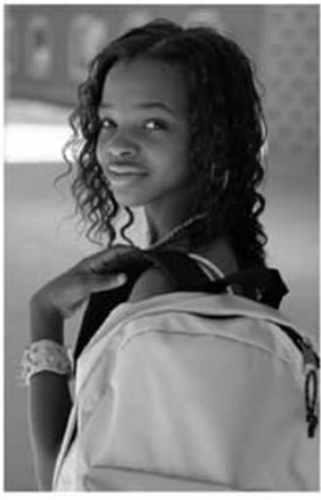

Image ID: 188858 Image Provider: OnRequest inages License Status: Active License

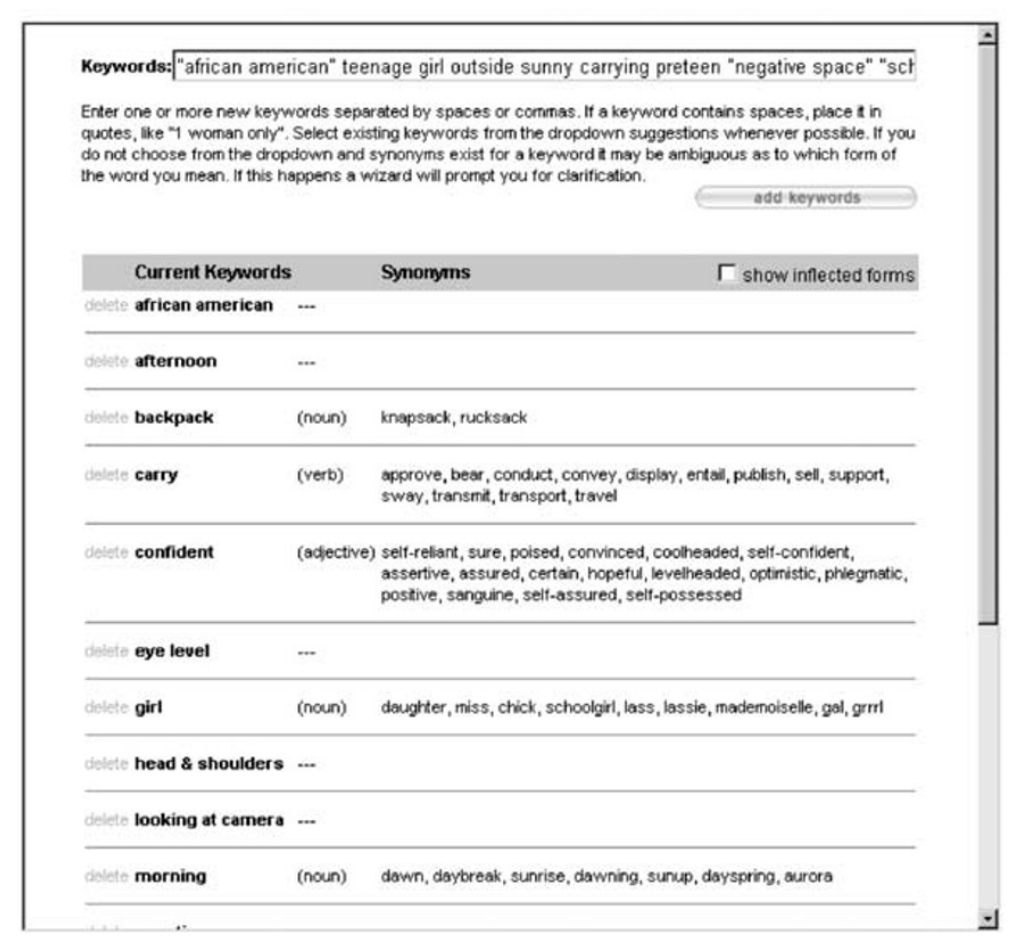

Figure 2: The screen capture above demonstrates one aspect of keyword complexity. In addition to the standard keywords that a single image requires, there are dozens of derivations that must be indexed for every image in a library

it. Image management systems require a visual interface - either using thumbnails or filmstrips or some other mechanism where a searcher can quickly view a low-resolution version of the image to determine its suitability (Figure 1).

The metadata needs for effective image management are extensive. Depending on the sophistication of the company and its image needs, deploying an image management solution may require a variety of metadata tags more robust than those required for other types of digital assets. Decisions about keywording and thesaurus definitions have tremendous impact on the usability of the image management system as they directly impact the relevance of search results.

The metadata for an image can be extremely complex. In addition to basic information such as subject, author, file format and size, other characteristics of the image that are essential to include are:

- License terms including permissions, specific geography restrictions, term of license, etc.
- Descriptive keywords that detail the image contents, for example: family, children, playing, outdoor, garden.

- Conceptual keywords that further describe the image such as: happy, closeness, freedom, etc.

- History of use such as campaigns the image was used in, products the image was supporting, customer segments that may have already seen the image, etc.

Standards for keywords are also critical. The structure and consistency of information is important to the relevance of image search results. For example, if an image of a cruise ship is keyworded with "ship" what happens if a searcher types in "boat"? Will a search on "boat" retrieve all items related to that term? The form of the word carries meaning as well. For example, if the user searches for "send," a synonym of the verb ship as in "to ship a package," would they find boats? In addition, a robust image management system must be able to account for the many variations of a single 
keyword (tense, plurals, synonyms, etc.) without having to manually add every derivation to the underlying database (Figure 2).

\section{Process management}

Managing an image library requires a very specific skill set. Staff members need to understand image license agreements and copyright infringement rules, be able to negotiate image pricing with agencies and suppliers, understand file formats and size requirements, as well as have an aesthetic eye for images that are on-brand.

These specialized skills are far easier to create by training a few people to manage the collection than by asking all users of images across the company to understand these details. Deploying a hosted solution allows a small group within the company to manage access and track use without having to be responsible for the development and management of the software solution. Time to market is greatly shortened and the company focuses on its brand and marketing, not the detailed information technology required to manage its images.

Some companies report they have been able to manage a hosted system with one-third the amount of staff they would need to handle the image management process entirely in-house. As a corporate risk management tool, an image management system administered by a centralized team can significantly reduce corporate liability through the close tracking of the company's use of imagery.

\section{SIDEBAR - THE VOICE OF EXPERIENCE: A LEADING FINANCIAL SERVICES COMPANY}

Here is the experience of one Fortune 100 company as they came to understand the complexity and resource requirements of developing and deploying an image management system.

Several years ago, when our company found itself facing potential liability for using an image in a marketing campaign without the appropriate license rights, we realized that there were many images in use across the company and we had no central visibility to the associated rights.
Coincidentally, at around the same time, we were about to launch a new initiative designed to strengthen the company's brand, and this included a desire to have closer control of the images used to represent the brand in our marketing and advertising collateral. We decided it was time to gather all our image assets together in one central place where they could be evaluated and then managed with an understanding of the associated license rights and permissions.

The consolidation effort alone was enormous, as we had to gather images from many different divisions and teams across the company. The company's collection today numbers more than 8,000 images. Once the images were gathered in one place, it quickly became clear that we could not manually manage all the images and associated rights. We needed an asset management solution to help us manage everything from a central location and reduce our liability for image use.

At the time we began this process and started planning to purchase image management software, the existing solutions on the market were not as robust as we would have liked. The initial project scope included detailed product research, contract negotiations with the software vendor, and the implementation process. While no single solution met all of our needs, we selected one that we felt would give us a base to work from.

The time it took for this initial phase of the project, from completing the consolidation of our image assets to the deployment of the image management software solution, was about one year and the cost ran into the hundreds of thousands of dollars. Key factors that we considered essential to an image management solution included the ability to customize the user interface, have extensive metadata fields, have access to detailed reporting of image retrieval and use, and to have a good user experience overall.

The software we purchased could not meet all our needs for detailed tracking of contracts and license permissions, so the company undertook an additional development effort to create a 'front end' transaction engine to augment the off-theshelf software package. In the first year we estimate we gained half a million dollars in costsaves from avoiding duplicate license fees and from having a faster, more efficient delivery system.

Additionally, since implementing the image management system, we have significantly reduced the risk of liability from inappropriate image use. 
The team that oversees this image management system plays an important role in the company's risk mitigation strategies, and the department has won ongoing budget support, even when budgets were cut across other corporate functions.

- Senior Manager, Brand Photography

\section{SIDEBAR - THE VOICE OF EXPERIENCE: A MAJOR MEDIA ENTERPRISE}

Back in 1995, we decided to implement an image management system. We were early adopters of this type of technology because as a media company we are big consumers of images.

During the nineties, we had a front row seat as the industry shifted from an analog (film) based model to an all digital one. As this change unfolded, we increasingly saw that we needed to be able to store, retrieve and view our images online.

We began researching systems that could handle the nearly 10,000 images we had in our collection at that time (comprised of wholly owned and public domain images, along with some licensed imagery).

Because we use images so regularly, it was imperative that the image management system worked as an integrated part of our overall workflow. Search, retrieval and display capabilities were critical. We also required the ability to caption and keyword our images with robust data sets.

After our initial research effort we determined that a hosted system was the right way for us to go. A hosted system allowed us to focus on what we knew best (our business) and keep our internal resources focused on the high-value work of selection/approval, captioning and production. Additionally, an online system enabled staff in our remote offices easier access to images in real-time

- no more overnight mailing of CD-ROM disks.

Today, our image collection numbers more than 200,000 images. Our system tracks the use, permissions (if any) and key metadata about the image. A team of five people can manage the entire image collection because our management system is hosted by a third party. An in-house solution could have easily doubled our staffing needs.
By implementing an image management system we have saved millions of dollars through increased productivity and reduced cycle times, cost savings in terms of staffing, and reduced liability for lost or damaged image transparencies (film).

- Director, Photo Services

\section{THE FUTURE OF IMAGE ASSET MANAGEMENT}

Enterprise-class Digital Asset Management (DAM) solutions may be able to manage image assets alongside other types of assets, however, their design is typically pre-set for broad application and they may be difficult to customize for the unique attributes of image files. Large corporations with the budgets, time and dedicated staff may find integrated, enterprise-class DAM systems deliver value through broad integration of assets andworkflows. The cost for return on this investment, however, is often quite high, and the risks of such large endeavors are many.

Many companies consider it wise to have a dedicated image management system optimized to reduce liability, provide simple, robust and visually optimized search capability and serve up images to a variety of audiences and geographies in a controlled and secure manner.

Early off-the-shelf image management software can be costly to implement if the standard package does not have the ability to deliver functionality that is required by the company.

Even with a software package that offers all the required capabilities, the complexity and cost of managing in-house systems and processes make it very attractive to use hosted image management services that specialize in this type of work, including all the particular skills required in the image management process. Particularly interesting are the new breed of companies that are both creating on demand custom image content as well as providing the hosted services to allow companies to manage this and other images long term.

As companies increase their understanding of the need to control and manage their image assets, more will be turning to image management solutions that are tailored to meet the unique needs of this complex asset class. 
More sophisticated tools and processes will lead to reduced corporate liability and better control of the company's brand - providing tangible ROI for companies who implement an image management system.

\section{Glossary of terms}

\begin{tabular}{ll}
\hline Comp image & $\begin{array}{l}\text { An image used for composition } \\
\text { or placement - temporarily } \\
\text { placed in a layout to help } \\
\text { designers choose the right } \\
\text { image. No license is necessary } \\
\text { for this use. }\end{array}$ \\
Custom & $\begin{array}{l}\text { Also know as "commissioned" } \\
\text { or "assignment" photography. } \\
\text { Created for a specific client or }\end{array}$ \\
& $\begin{array}{l}\text { specific use, on request. } \\
\text { Image license }\end{array}$ \\
& $\begin{array}{l}\text { The legal permission given by a } \\
\text { photographer or agency for use } \\
\text { of an image. The license can re- } \\
\text { strict length of time, geography, } \\
\text { placement, size, industry and } \\
\text { other factors. }\end{array}$
\end{tabular}

\begin{tabular}{ll}
$\begin{array}{l}\text { Rights } \\
\text { managed }\end{array}$ & $\begin{array}{l}\text { Photography that is licensed for } \\
\text { specific use. Violations of the } \\
\text { license for inappropriate use can } \\
\text { create significant liability. }\end{array}$ \\
Royalty free & $\begin{array}{l}\text { Photography that has a multiple- } \\
\text { use license. Images may be used } \\
\text { multiple times, in many different } \\
\text { ways without a specific permis- } \\
\text { sion for each use. }\end{array}$ \\
$\begin{array}{l}\text { Stock } \\
\text { photography }\end{array}$ & $\begin{array}{l}\text { Image collections managed by } \\
\text { photographers or agencies that } \\
\text { are pre-existing rather than cus- } \\
\text { tom created for a specific client } \\
\text { or use. }\end{array}$ \\
\hline
\end{tabular}

\section{Notes}

1 Depending on whether or not the company shot the image with in-house resources or assigned the work to an outside photographer who might retain some rights.

2 Daryl Lang, PDN Online, September 12, 2005 http://www.pdnonline.com/pdn/search/article_ display.jsp?vnu_content_id=1001096883. 